\title{
Community-Based Service-Learning in Language Education: A Review of the Literature
}

Lottie Baker

The George Washington University 


\title{
Community-Based Service-Learning in Language Education: A Review of the Literature
}

\author{
Lottie Baker \\ The George Washington University
}

\begin{abstract}
Community-based service-learning (CBSL) is increasingly utilized in the second language (L2) education field as a strategy for learners to interact with target language communities. Accompanying the growth of CBSL in L2 is the need to examine and critique research and practice. This systematic literature review describes CBSL research in higher education L2 settings to understand program implementation, associated outcomes, and lessons learned. The review represents 69 articles published between 1997 and 2017. Trends in CBSL reveal a variety of CBSL experiences for L2 learners, with most programs representing a U.S. Spanish language context. Students stepped out of university classrooms to tutor children at elementary schools, to interact with immigrant adults at community centers, and to contribute to professional agencies using languages for specific purposes. Thirty-nine of the articles were empirical studies with outcomes that addressed L2 learners' gains in linguistic proficiency, cultural understanding, motivation and interests related to language learning, and/or civic engagement. Overall, the literature review demonstrated positive associations between CBSL and student outcomes in L2 education. In an era of a growing number of CBSL programs, this review serves as a resource for research-based practices and as a springboard for new research.
\end{abstract}

Keywords: community-based service-learning, language education, literature review

Community-based service-learning (CBSL) intuitively complements second language (L2) education; regular, meaningful interaction with native speakers promotes learners' communicative proficiency goals (Thompson, 2012). These in-person exchanges are increasingly accessible to college students without requiring study-abroad sojourns. "New destination" areas, or nontraditional geographic spaces in which immigrants locate, have been on the rise in the United States since the beginning of the 21st century (Suro \& Singer, 2002). As they settle in these areas, immigrants and their families bring linguistic and cultural diversity to otherwise monolingual suburban and rural towns, generating potential encounters among speakers of different languages. CBSL holds promise for universities to contribute to the neighborhoods in and around which they are situated while providing learners with opportunities to use authentic L2 for professional and practical purposes. This literature review takes stock of existing research to uncover knowledge about CBSL in L2 higher education that can inform directions for practice and further study. It comes at an opportune time, particularly in the United States.

While community engagement is not a new phenomenon in L2 education (e.g., Rabin, 2011), national standards and declining enrollment in L2 education make CBSL a growing practice on U.S. campuses. The creation of national professional standards published by the American Council on the Teaching of Foreign Languages (ACTFL) in 1996 elevated CBSL to prominence. The standards move beyond teaching students "how (grammar) to say what (vocabulary)" to a more complex construct of communication that "highlights the why, the whom, and the when" (National Standards, 1996, p. 2, italics in the original). Most recently updated in 2015 as the World-Readiness Standards for Language Learning (W-RSLL), the standards are organized by five goal areas (the "5 C's"): Communication, Cultures, Connections, Comparisons, and Communities. Each of these goal areas emphasizes language use in context rather than isolated linguistic knowledge. 
The Communities goal area challenges faculty to incorporate into their teaching interaction with local and global multilingual speakers. Authors of a 2011 report on the impact of ACTFL standards on K-16 L2 programs concluded that teachers found "the [Communities] goal area to be nebulous, out of their control, and not assessable" while also noting increased interest in higher education for "service learning initiatives on campuses" (Phillips \& Abbott, p. 11). Abbott and Lear (2010) likewise suggested that engagement in community service-learning makes "the Communities goal area suddenly impossible to avoid instead of difficult to implement" (p. 232). Given the centrality of community engagement in the ACTFL standards, CBSL scholarship is particularly important in L2 education.

Further, CBSL can make language study relevant for college students, many of whom increasingly demonstrate a lackluster interest in language majors. The Modern Language Association (MLA) reported a $6.7 \%$ decline in the enrollment of students in language programs from 2009 to 2013, the first-ever downward trend since the MLA started collecting survey data in 1958 (Goldberg, Looney, \& Lusin, 2015). The reduction of L2 enrollment persisted, as indicated in the MLA's 2016 report, with a 9.2\% drop in college student enrollment from 2013 to 2016 (Looney \& Lusin, 2019). Few students study languages with plans to complete majors and pursue graduate degrees in literature, opting instead to gain proficiency in meeting the multilingual communicative competence that 21st-century careers demand (MLA, 2007).

In response to this shifting landscape, L2 educators are embracing CBSL approaches that engage students directly with the community (Brown \& Thompson, 2018). The prevalence of CBSL has been evidenced through anecdotal accounts in the literature of CBSL in L2 (e.g., Hellebrandt \& Varona, 1999), the publication of language education textbooks focusing on CBSL (e.g., Comunidades by Abbott, 2009), the prioritization of the topic in professional journals (e.g., Hispania), and the mounting calls for increased research and practice in the area (e.g., Palpacuer Lee, Curtis, \& Curran, 2018). Although the field of L2 suffers from a lack of empirical CBSL study compared to other disciplines (Yorio \& Ye, 2012), research in L2 education is on the rise. Reviewing existing scholarship can inform and serve as a roadmap for upgrading, adapting, and creating CBSL experiences in L2 programs. This literature review seeks to uncover work on CBSL in higher education L2 contexts, with the ultimate goal of describing the state of the field, distilling promising practices, and making recommendations for future work.

For the purposes of this review, I operationalize CBSL using Zlotkowski's (1998) broad definition: "community service that is linked to students' academic experience through related course materials and reflective activities" (p. 3). This definition aligns with others in the L2 field (Abbot \& Lear, 2010). Other terms capture nuanced understandings of the concept (e.g., servicelearning, community-engaged learning), but in general, the concepts share the three characteristics of service-learning, reflection, and reciprocity (e.g., Bringle \& Hatcher, 1996; Jacoby \& Associates, 1996).

\section{Methods for the Literature Review}

Scholars define systematic literature reviews variously in the field (e.g., Hammersley, 2001; Kennedy, 2007); however, one agreed-upon distinction of systematic reviews is their methodological process for identifying and analyzing literature to inform a specific research question, as opposed to "haphazard selection procedures" (Slavin, 1986, p. 6). This review adheres to principles proposed by Evans and Benefield (2001), who adapted characteristics of systematic reviews in the medical research field to education settings. These principles include a clear specification of the research question to be addressed; systematic and exhaustive searching for studies; clear criteria for including and excluding studies; assessments of methodological quality of studies; strategies to reduce bias in selection and reviewing; and transparency of the methodology for carrying out the review (p. 533). 
The research questions for this review were: How has CBSL been implemented in L2 higher education settings? What outcomes have CBSL L2 research revealed? What implications does the literature offer for practice?

\section{Search Process}

Inclusion criteria for this review included articles that: (a) addressed the topic of CBSL in language learning contexts as a central part of the article; (b) focused on postsecondary settings; and (c) were published in scholarly/peer-reviewed journals. I utilized one general academic database (i.e., Academic Search Complete [ASC]) and three subject-specific databases (i.e., Education Resources Information Center [ERIC], Education Source, and PsycArticles). I initially limited the search to strictly empirical research. However, I found numerous program descriptions, evaluations, theoretical pieces, and reflective self-studies that did not include a detailed methodology section but still offered relevant insight into the research questions. I excluded book reviews, short opinion pieces, and summaries of conference proceedings.

A process of trial and error and reviewing the database thesauri led me to settle on the following keywords for maximum relevant results: (1) community-based learning OR service-learning and (2) foreign language OR world language OR language learning. I also excluded the large and growing body of work on CBSL in TESOL (e.g., Perren \& Wurr, 2015) unless the article focused on improving teachers' target language proficiency or cultural knowledge. The search was not limited by year of publication. Articles that met the inclusion criteria spanned a 20-year period: from 1997the year following ACTFL's inaugural publication of its national standards - to 2017. A noticeable increase in articles published per year was seen beginning in 2008. Many of the articles were published in The Foreign Language Annals $(\mathrm{n}=14)$ and Hispania $(\mathrm{n}=22$, including 10 articles in a special themed issue published in 2013).

Initial search results with duplicates omitted yielded 237 articles. I excluded articles that focused on teacher education rather than language education. I reviewed titles and abstracts of each to ensure they met the inclusion criteria and further reduced the number of relevant articles to 91 . I obtained full-text versions of all 91 articles and subsequently narrowed the corpus to 69 articles. ${ }^{1}$

Conducting research using online databases presents inherent limitations (Kennedy, 2007) due to limited access to databases and manuscripts indexed within these databases. I attempted to capture a wide selection of articles by using both general and subject-specific databases in the field of education, but these databases excluded potentially relevant work in disciplines tangentially related to education, such as arts and humanities. I selected databases relevant to education because one goal of the review is to improve L2 instructors' capacities to integrate CBSL as a pedagogical technique. I analyzed only articles published in English and therefore may have privileged studies in the United States, Canada, or other English-speaking countries. While international work may have been excluded, the rationale for the review emerged from the enrollment trends in U.S. L2 higher education contexts. I also excluded conference papers and dissertations, as acquiring them is challenging and inconsistent. Because the peer-review process for books is not typically as rigorous as for peer-reviewed research journals, I included publications from scholarly journals only.

\section{Analysis}

Analysis of the 69 articles comprised an iterative process in which I read, analyzed, coded, and synthesized content of each article. I uploaded the full text of each article into the qualitative analysis software ATLAS.ti to record codes related to context, methodology, and findings. From the coded articles, I developed a spreadsheet containing information about each article, including the year published, target language, location (i.e., city or description of area), and learner population. For empirical studies, I recorded the following research features in separate columns: research question, methodology (i.e., qualitative, quantitative, or mixed), data sources (e.g., interviews, surveys), number and description of participants, major findings, and implications. In the final column, I listed 
relevant information about the study that was not captured in the preceding features. I labeled the methodology as "theoretical" for conceptual pieces, "descriptive" for program descriptions, and "editorial" for articles that provided recommendations for best practice.

Adapting the constant comparative method for qualitative data analysis (Glaser \& Strauss, 1967), I analyzed articles across features in an iterative manner to identify themes that addressed the research questions. Specifically, I examined articles to understand CBSL implementation in L2 higher education settings. I reviewed the codes relating to university contexts, community agencies, and tasks performed, and combined similar codes into themes. Within the empirical studies, I attended to the kinds of outcomes that authors reported, again combining codes into themes. Finally, I identified areas for future practice and study as described by the authors of the articles.

Of the 69 articles represented in this literature review, less than half $(n=29$, or $42 \%)$ were empirical or included a methodology section with a systematic line of inquiry (e.g., research questions) and description of data collection and analysis. The remaining 40 articles were descriptive - that is, the authors described programs, provided practical suggestions for others in the field, or discussed general trends in CBSL without reporting on systematically gathered data that responded to a research question. All articles informed this review, but the 29 studies and their findings were prominent, especially regarding the second research question about outcomes of L2 CBSL.

In the following sections, I first summarize how CBSL has been implemented in L2 settings, focusing on institutional and community contexts. I then turn my attention to the 29 empirical articles to examine the kinds of outcomes CBSL research has identified in L2 education. Finally, I synthesize implications for CBSL in L2 settings that may be applied to other disciplines and conclude with areas for further study.

\section{Descriptive Characteristics of Articles}

\section{Institutional Contexts}

As per the search parameters, all articles discussed CBSL in the context of higher education institutions. While the search was open to include community college settings, authors described their institutions as either four-year undergraduate or graduate programs. Within these universities, contexts varied by language, geographic location, and curricular placement of the CBSL experience.

Target language and location. The large majority of authors $(n=54$, or $78 \%)$ addressed undergraduate Spanish language education, most of which was based at colleges or universities within the United States or Canada. Non-Spanish language instruction included English $(n=6)$, French $(n=3)$, German $(n=2)$, Italian $(n=1)$, and Arabic $(n=1$; this study also addressed Spanish language learners); the remaining articles addressed CBSL and L2 in a general sense without referring to particular languages. Studies conducted outside the United States or Canada were from Turkey, Serbia, New Zealand, Ireland, Egypt, and Taiwan. English was the target language in these studies, with the exception of Jovanović and Filipović's (2013) program description of Spanish language learners in Serbia and O'Connor's (2012) description of Italian-language learners in Ireland. The dearth of studies in international contexts does not necessarily indicate that CBSL is not occurring in countries outside the United States, but the search constraints (e.g., search terms, databases) may not have captured the full range of international studies.

Seven articles (i.e., Carracelas-Juncal, 2013; Leeman, Rabin, \& Román-Mendoza, 2011a, 2011b; Llombart-Huesca \& Pulido, 2017; Martínez \& Schwartz, 2012; Pascual y Cabo, Prada, \& Lowther Pereira, 2017; Petrov, 2013) gave special attention to the considerations of Spanish heritage language learners (HLLs), or those students who are "raised in a home where a non-English language is spoken ... and who [are] to some degree bilingual in English and the heritage language" (Valdés, 2000, p. 1). A focus on Spanish HLLs was relatively recent, with articles only appearing after 2011. 
Connection to curriculum. Within the articles reviewed, the majority of CBSL experiences were associated with L2 courses that addressed learning the target language and culture, and the CBSL component was usually mandatory. From their review of 40 Spanish L2 CBSL curricula, Barreneche and Ramos-Flores (2013) identified three primary ways universities situated CBSL in their Spanish language major programs: (a) mandatory and integrated for all majors; (b) special track within the major; and (c) elective for majors. However, not all articles focused exclusively on programs for L2 majors. Miano, Bernhardt, and Brates (2016), for instance, described a summer CBSL experience designed to encourage science and math majors to pursue advanced language study. CBSL experiences tended be associated with students in intermediate- or advanced-level language courses, with a handful of these courses focused on specific topics, such as film (Larson, 2015), entrepreneurial business (Abbott \& Lear, 2010), or medicine (Martínez \& Schwartz, 2012). An exception was Bloom's (2008) case study with students in a beginning-level Spanish class who worked with native Spanish-speaking pupils at a local school and wrote reflections in their L1 (English).

Three articles addressed teacher education courses that were designed to prepare pre-service teachers to instruct the L2 (i.e., Carracelas-Juncal, 2013; Hummel, 2013; Jovanović \& Filipović, 2013). In these cases, the pre-service teachers were not native speakers of the target language that they would later teach; the CBSL was designed to enhance their target language proficiency. A few authors described how CBSL was integrated at the program level, either through an internship capstone experience (e.g., Martínez \& Schwartz, 2012) or through a faculty effort to revitalize the major (e.g., Leeman et al., 2011a).

\section{Community Contexts}

Authors identified over 70 different community partnerships. In some cases, a "partnership" constituted one agency or school, while in other cases a "partnership" referred to a university's connection with multiple agencies and/or schools. In many of these cases, students were responsible for seeking out these community partners. The kinds of partners varied, and the often vague descriptions of community agencies made understanding the specific partnerships difficult. Education institutions (e.g., K-12 schools and adult education classes) represented many, but not all, of the partnerships. The tasks that L2 students performed depended on the community partner and goals of the L2 program.

K-12 schools. About one-third of the partnerships $(n=21)$ were exclusively with K-12 schools. In Bettencourt's (2015) study, Spanish language students worked in after-school programs to assist teachers and to tutor students in Spanish. Grim's (2010) French language students designed and implemented lessons for elementary students learning French under the university faculty member's guidance. By contrast, Bettencourt's (2015) Spanish language students did not prepare lessons; instead, they assisted K-12 teachers on the spot with tasks involving Spanish-speaking students, such as playing with or tutoring students and helping liaise with families. In yet another example of a partnership with a K-12 school, Bugel (2013) described how students played the role of translators or interpreters for Spanish-speaking families.

Some authors described Spanish language students who supported English learning for Spanish speakers. Carney's (2004) students, for instance, spent two to three hours per week as "academic tutors and mentors" (p. 268) to students in English as a second language (ESL) classes, and Pellettieri's (2011) students tutored beginning Spanish speakers learning ESL. While supporting English language may seem contradictory to the learning goals of Spanish students, Pellettieri posited that the situation was ideal for intermediate students who were not comfortable communicating exclusively in Spanish. Varona (2006) also found that tutoring adults in ESL increased students' metalinguistic knowledge. She said that when her Spanish students "explain to their adult students the intricacies of English syntax, they only have to remember the process they are going or have gone through in their Spanish classes" (p. 209). 
As might be expected, the four articles with a teacher education context included school-based service-learning experiences. These examples went beyond standard student teaching internships; the university students provided the school with a service that would otherwise not be available. For instance, Jovanović and Filipović (2013) described how Spanish classes provided in Serbian schools were often the result of grassroots efforts and activism from teachers or the community. To support Spanish classes, the authors facilitated a series of two-week Spanish language workshops that their teacher education students implemented with adolescents at two public high schools. The authors characterized their service-learning workshops as examples of community efforts that bring "a Spanish language course in schools where this sort of instruction had not been available previously" (p. 289).

Adult education. Authors also partnered with adult education agencies $(n=8)$. In many of these instances, Spanish language university students served as English tutors for adult Latinx students in GED, literacy, or ESL classes. For instance, Miano et al.'s (2016) Spanish language students helped immigrants prepare for the citizenship examination in Spanish as part of a two-week intensive Spanish course held in the summer. López's (2014) intermediate-level Spanish language students also supported Latinx adults preparing for exams. López collaborated with the local literacy council for students to serve as assistants in class or to tutor one-on-one in preparation for either the GED or the citizenship exam. Her students participated throughout the semester and received training from the literacy council.

Varricchio (2006) partnered with a local business to support adult language learning. She described how students in an advanced Spanish phonetics course tutored Hispanic food-service employees in a local company. Students received training for teaching English and then worked in pairs to prepare and deliver lessons relevant to the needs of the employees. Teaching English provided opportunities for students to reflect on differences between the sound systems of Spanish and English. Frame and Ballah (2015) offered an example from a French L2 context, the only nonSpanish language example of partnering with adult education in my sample. They described an intergenerational partnership in which intermediate French students taught introductory French classes for older adults in the community. In Frame and Ballah's project, the students taught a regular class for adults who came to the university rather than the students traveling to a site in the community.

Two studies' authors (d'Arlach, Sánchez, \& Feuer, 2009; Medina \& Gordon, 2014) utilized language exchanges as means for students to interact with native-speaking adults in the community. In these situations, students met with native speakers in the community who wanted to practice English, alternating between speaking the target language and English so that both the student and the community partner gained conversational practice. d'Arlach et al. implemented exchanges in a class consisting of 10 Spanish language students and 10 immigrants from the community. They facilitated weekly three-hour sessions using a combination of textbook exercises and reflective conversations on social issues. Medina and Gordon (2014) described how students in a Spanish language phonetics class met with Hispanic community members weekly for 60-minute sessions to practice oral conversation, with students and their community partners alternating languages during the session. Rather than leading a structured group conversation and using textbooks as d'Arlach et al. described, Medina and Gordon explained that the phonetics professor only monitored the sessions by offering conversation topics and indicating when partners should switch languages.

Virtual communities. Three authors discussed a CBSL experience using virtual technology (i.e., Ogeyik \& Guvendir, 2009; Sun \& Yang, 2015; ter Horst \& Pearce, 2010). None of these studies addressed took place in U.S. Spanish language instructional contexts, the most common L2 settings represented in this review. Ogeyik and Guvendir and Sun and Yang both worked with EFL learners in Turkey and Taiwan, respectively; ter Host and Pearce taught German in the United States. As ter Horst and Pearce stated, technology in CBSL is particularly relevant for non-Spanish language instruction, "for which local communities often do not exist, or to nonurban areas" (p. 367). These authors demonstrated the potential for technology to expand the notion of community beyond the 
neighborhood surrounding the university, a trend likely to continue with the growing availability of mobile devices and Internet access.

Other partners. Other settings for CBSL included health clinics, agencies that serve older adults, and family visits. Some of these programs used CBSL to support student learning in language for specific purposes such as using medical Spanish (Martínez \& Schwartz, 2012) or business Spanish (Abbott \& Lear, 2010; Bugel, 2013). CBSL activities also included supporting needs within the university. For instance, students learning English as an L2 in Taiwan created English language online orientation materials for international students (Sun \& Yang, 2015). Likewise, Spanish L2 students interacted with Spanish speakers who attended Saturday sessions at a university-sponsored "Latino Learning Center" (Moreno-López, Ramos-Sellman, Miranda-Aldaco, \& Quinto, 2017). Larson (2015) described taking part in a university-wide student philanthropy project in which students "select, research, and evaluate nonprofits" in order to allocate funds that support community needs. She integrated the project in an advanced Spanish L2 course on Hispanic film studies. Students viewed 12 Spanish language films related to four social issues. They worked in groups to research one of the four themes and identified local nonprofit organizations addressing the theme's social issue. Student groups selected organizations they felt would benefit from the funding award and negotiated as a class to determine how to allocate the award to local groups. Through this process, students learned first-hand about the local context of the social issues they encountered in the films and gained experience advocating for nonprofit organizations that intersect with the Spanish-speaking community.

The range of community partnerships represented in the literature indicates the potential for CBSL in L2 settings. Community contexts not only varied by location (e.g., K-12 schools, community agencies, online), but also in the kind of work they provided to L2 students. Authors described successful partnerships that involved a high degree of structure, facilitation, and training from university faculty or community leaders, as well as those that involved students simply "showing up" to help out with general tasks. No particular kind of partnership emerged as more successful than others, but the kinds of student outcomes varied depending on the type of partnership and CBSL work conducted. Therefore, I next turn to outcomes discussed in the empirical articles.

\section{Empirical Studies: Outcomes in CBSL Research}

\section{Research Methods}

I analyzed empirical articles $(n=29)$ for outcomes in CBSL L2 courses. The majority of these articles utilized qualitative $(\mathrm{n}=15)$ or mixed $(\mathrm{n}=13)$ methodological approaches, with one study (i.e., Medina \& Gordon, 2014) employing exclusively quantitative methods. Instruments included pre/post questionnaires, reflective prompts, or surveys on perceived learning. Authors varied in the level of detail they provided about instruments; some included the instruments as appendices, others referred to widely used protocols (e.g., Bettencourt's [2015] use of DEAL), while still others simply described their instruments as "reflective prompts." Well over half of all studies $(n=19$, or $66 \%)$ reported on course assignments (e.g., written reflections). In eight articles the authors identified themselves as the course instructors and investigated the extent to which course goals were met through CBSL. Table 1 lists the empirical studies by methodology.

Common theories undergirding these articles were social constructivism, which suggests that knowledge is co-created through interaction (e.g., Hummel, 2013; Sun \& Yang, 2015); critical pedagogies that position language learning as a means to disrupt the status quo (e.g., d'Arlach et al., 2009; Martínez \& Schwartz, 2012); and cultural competence, which highlights the importance of understanding various aspects of culture alongside language (e.g., Bloom, 2008; King de Ramirez, 2015). While not a theory per se, the ACTFL "5 C" goal areas served as a framework for three studies (i.e., Abbott \& Lear, 2010; Bettencourt, 2015; Wehling, 2008) and informed the findings or conclusions of five others (i.e., Grim, 2010; Jorge, 2011; Llombart-Huesca \& Pulido, 2017; Martínez 
8 International Journal of Research on Service-Learning and Community Engagement

\& Schwartz, 2012; ter Horst \& Pearce, 2010). Sample sizes ranged from three (Carracelas-Juncal, 2013) to 160 (Jorge, 2011), with 34 as the mean number of participants. The study with the largest sample size (Jorge, 2011) was also the only study that followed students longitudinally after graduation to understand long-term impacts of CBSL programs.

Table 1. Empirical Studies by Methodology

\begin{tabular}{lll}
\hline Qualitative Methods (n= 15) & Mixed Methods (n= 13) & Quantitative Methods (n=1) \\
\hline - Abbott \& Lear (2010) & - Bettencourt (2015) & • Medina \& Gordon (2014) \\
- Andrew (2012) & - Bloom (2008) & \\
- Barreneche (2011) & - Elorriaga (2007) & \\
- Barreneche \& Ramos-Flores & - Jorge (2011) \\
- Bowen \& Hackett (2010) & - Larson (2015) \\
- Carracelas-Juncal (2013) & - Miano et al. (2016) \\
- D'Arlach et al. (2009) & - Morreno-López et al. (2017) \\
- Frame \& Ballah (2015) & - Pascual y Cabo et al. (2017) \\
- Grim (2010) & - Pellettieri (2011) \\
- Hummel (2013) & - Petrov (2013) \\
- King de Ramírez (2015) & - ter Horst \& Pearce (2010) \\
- Llombart-Huesca \& Pulido & - Zapata (2011) \\
- Long (2017) & \\
- Martinez \& Schwartz (2012) & \\
\hline
\end{tabular}

\section{Outcomes}

All but two of the empirical studies presented findings about student outcomes $(n=27)$. Common student outcomes represented in these studies were those related to students' perceived or observed linguistic proficiency $(\mathrm{n}=16)$, cultural understanding $(\mathrm{n}=11)$, motivation and interest in L2 $(\mathrm{n}=$ 11), and civic engagement $(n=6)$. Other outcomes related to specific content knowledge, professional careers, or general personal growth $(n=5)$. Five empirical articles examined student outcomes specific to Spanish HLLs (i.e., Carracelas-Juncal, 2013; Llombart-Huesca \& Pulido, 2017; Martínez \& Schwartz, 2012; Pascual y Cabo et al., 2017; Petrov, 2013). The range of student outcome types suggests that linguistic proficiency is not the sole goal of language classes, at least for those included in this review; cultural competency, attitudes, and language use in professional settings also emerged as L2 goals. Figure 1 displays the frequency of student outcomes represented across the empirical studies. ${ }^{2}$

In general, the findings indicated that CBSL is associated with positive student outcomes. Even when measured gains were marginal or statistically insignificant, authors still concluded that CBSL held potential for language learners (e.g., Medina \& Gordon, 2014). Such positive outcomes of CBSL would theoretically be expected, given the correlation between language learning and immersion-like experiences with native speakers (Thompson, 2012), but these trends may reflect a bias of authors or journal editors who are invested in expanding CBSL work in language education. A close examination of findings, with attention to the data sources and context of the CBSL 
experience, can help practitioners interpret these outcomes and apply findings to their own work. I next describe in further detail findings for each outcome.

Figure 1. Student outcomes in empirical studies (number of studies).

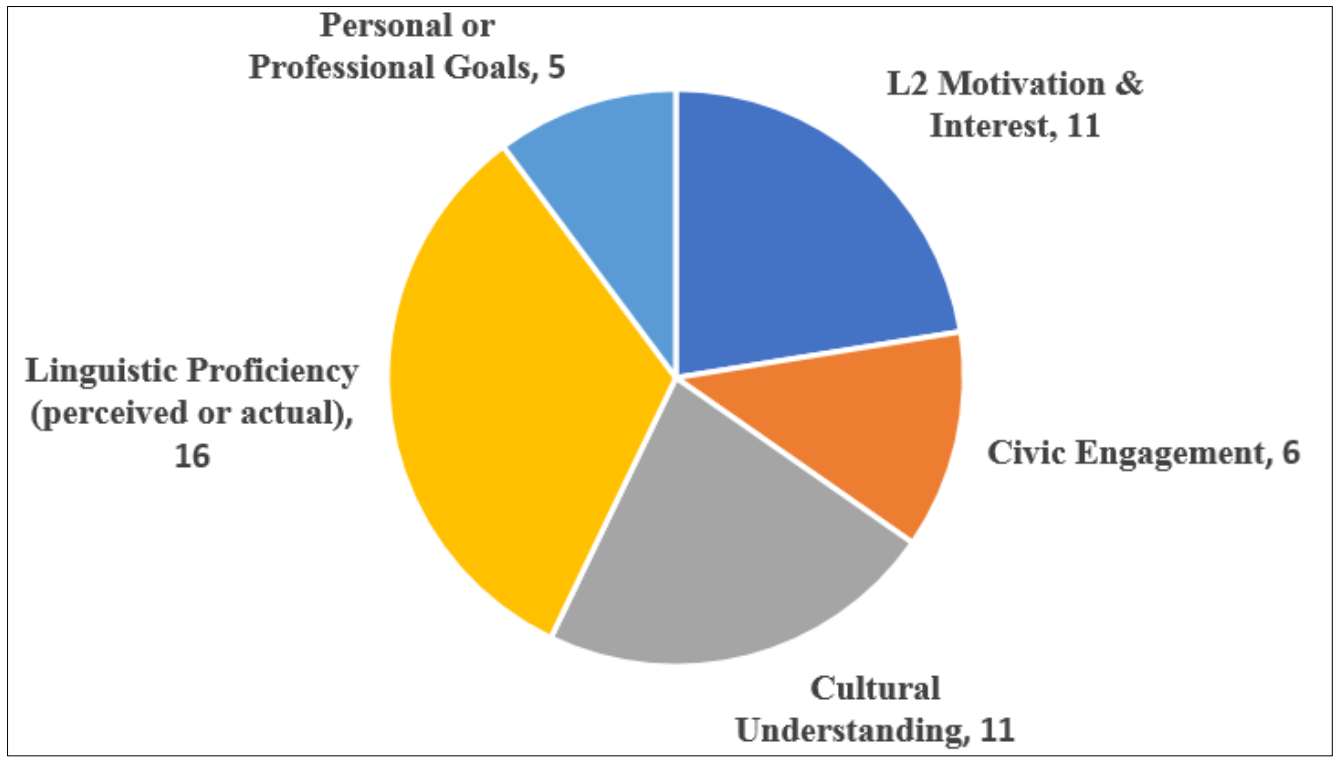

Linguistic gains. The majority of the 16 studies that examined linguistic outcomes captured perceived language growth $(\mathrm{n}=12$, or $75 \%)$; on Likert-type survey items or on responses to openended journal prompts, students reported the extent to which they felt their language skills improved. In these studies, students reported gains in their language acquisition largely related to Spanish use outside the classroom. For instance, Elorriaga (2007) collected the reflections of 16 Spanish language students who tutored Latinx parents in their homes once per week. She found that students reported learning "a lot of vocabulary that otherwise they would not have learned in a regular Spanish class" (p. 537). Pellettieri's (2011) 18 Spanish language students tutored ESL for beginning Spanish speakers. Results from a pre- and post- Likert-type survey suggested that students developed perceived language competence along with other affective components. Andrew (2012) conducted a qualitative exploration of four Chinese international students in New Zealand enrolled in English language coursework. They participated in a 10-hour CBSL experience, volunteering at rest homes, and wrote in weekly journals that addressed "their interactions in spoken English; the situations they found themselves in in which English was used; a record of their learning about language, culture, and society based on their placement; evidence connecting classroom learning with community placement" (p. 8). Students reported applying classroom learning to authentic settings and acquiring language in context, such as slang terms that may not be explicitly taught in the classroom.

Martínez and Schwartz (2012) and Pascual y Cabo et al. (2017) focused on reported linguistic gains of Spanish HLLs. Martínez and Schwartz described a medical Spanish course that required students to translate nutrition plans and participate in small-group diabetes education classes for Spanish speakers at local healthcare clinics. At the end of the semester, students completed an openended questionnaire that prompted them to reflect on their language use. The authors found that students "repeatedly discussed the challenges of on-the-spot translating, finding the right word, and of capturing the most fine-grained nuance" (p. 181). The experience presented HLLs with opportunities to draw on family resources to make meaning when translating or interpreting. For 
instance, the authors described how the task of translating the term shortening led one student to consult her family at home for help identifying a precise meaning appropriate for her audience.

Pascual y Cabo et al. (2017) investigated the extent to which a CBSL experience in schools influenced 26 Spanish HLLs' attitudes toward their language and culture. Students designed and delivered Spanish language lessons to elementary school students and completed a post-course reflective essay and survey that were analyzed for the study. Students commented that "being forced' to use Spanish in more diverse and professional settings helped them practice and use their language skills on demand and in a flexible and spontaneous manner, develop their linguistic repertoires, and gain confidence" (p. 81). The authors concluded that using Spanish meaningfully in public roles can strengthen HLLs' linguistic and cultural identities, which can, in turn, enhance motivation to develop their language skills.

Only four of the studies measured growth in language proficiency through proficiency or achievement assessments, rather than self-reports. These studies examined different aspects of linguistic proficiency, including oral and written skills, vocabulary and grammar knowledge, and phonetic perception. Unlike the majority of studies examining perceived outcomes, none of these four studies resulted in clear language proficiency gains.

Two of these studies examined linguistic proficiency through pre- and post- measures. First, in a virtual service-learning project in which German language students translated and adapted materials for a website on sustainable development, ter Horst and Pearce (2010) conducted a discourse analysis of student language production in two online discussion forums. The first discussion occurred at the beginning of the course and required students to introduce themselves and their backgrounds; the second occurred in the middle of the website project and required students to reflect on environmental issues they viewed as important. The authors found evidence of increased complexity in students' responses in the second discussion forum and suggested that the CBSL project contributed to their language growth. They also suggested that the topic of the second discussion required students to use more complex structures (e.g., subordination) to express their thoughts than the introductory discussion topic. However, the authors could not separate the impact of the project from other activities in the course.

Second, Miano et al. (2016) examined the growth of intermediate-level Spanish learners' $(n=$ 51) oral and written proficiency on pre- and post- assessments over the course of a three-week immersive summer experience. These students were all sophomores who intended to declare science or math majors. As part of the experience, students tutored Spanish-speaking immigrants for the U.S. citizenship exam two afternoons per week. Examining data collected over four summers, authors found that students at all levels demonstrated gains in both written and oral communication, with less-advanced students making more remarkable gains in writing than those who started the program with greater language proficiency. However, the absence of a control group made the precise role that the CBSL experience played in students' language proficiency gains uncertain.

Medina and Gordon (2014) and Moreno-López et al. (2017) both utilized comparison groups in their analyses. Medina and Gordon examined the extent to which participating in a nine-week CBSL experience influenced students' phonemic perception in Spanish on a pre- and post-, 100-item phonemic perception test. Of 25 participants in a Spanish phonetics class, 12 participated in a weekly language exchange option. Students wrote weekly reflections on pronunciation, new vocabulary, and cultural information. The authors found no significant differences between groups on phonemic perception, concluding that while CBSL "may be instructive and beneficial in some areas ... there is no statistical evidence as of yet in support of service learning over non-service learning in promoting L2 development" (p. 366). However, they also drew on students' reflections to suggest that conversing with Spanish speakers appeared to facilitate a focus on communicating for meaning rather than on perceptual differences between languages.

Lastly, Moreno-López et al. (2017) examined performance of Spanish language students through a locally constructed multiple-choice vocabulary and grammar assessment given at the beginning and end of the course. They assigned students to four learning conditions over one semester: 
traditional class $(n=67)$, service-learning $(n=9)$, telecollaboration $(n=43)$, and a three-week studyabroad class $(n=29)$. Students in the service-learning option interacted with Spanish-speaking residents at the college's Latino Learning Center each Saturday for one hour and submitted weekly online reflections. The authors found no significant differences among groups regarding linguistic gains. However, open-ended responses indicated that students who interacted with native speakersincluding those in the service-learning group - expressed more confidence and perceived more gains in oral communication than those in the other conditions.

Taken together, studies on linguistic outcomes revealed mixed findings on student language growth. Authors demonstrated that students perceived language growth as a result of CBSL, but the extent to which CBSL directly facilitated actual language growth is unclear and warrants additional investigation. All the researchers who measured linguistic outcomes through proficiency tasks or assessments called for repeated studies. They all advocated that CBSL activities align closely with the linguistic goals. At the same time, the findings on perceived language growth are not unimportant; Pelletteiri (2011), for instance, contended that the perception of learning is a meaningful outcome and has been shown to support actual language growth.

Cultural understanding. Eleven of the studies resulted in outcomes related to students' cultural growth. CBSL was associated with growth in cultural knowledge, largely, but not exclusively, through direct contact with community members. Authors approached the notion of culture in different ways. Long (2003), for instance, analyzed journals written by 11 Spanish language students who participated in various service-learning capacities, including tutoring Spanish-speaking pupils, interpreting at a hospital, and facilitating Spanish story hours. Long found that students demonstrated appreciation and characterization, the third and fourth stages of Valette and Disick's (1972) fivestage taxonomy, through the relationships they formed with Spanish-speaking individuals in the community. Bowen and Hackett (2010) reviewed qualitative data from students across two sections of a Spanish language service-learning class. The students worked with Spanish-speaking ESL pupils. Three themes emerged from their reflections: the importance of social interaction, an awareness of the "dual sense of reality" that ESL pupils felt, and a growth in tolerance and cultural understanding. Wehling (2008) also analyzed student journals for evidence of cultural competency. Her students conducted 40 hours of site visits with Latinx migrant families at their homes or in schools. From her analysis of 58 journal entries, Wehling concluded that service-learning enabled students "to move beyond cultural precompetence and toward cultural competence; first, by speaking Spanish outside the classroom; and then, by challenging their own assumptions and assessing themselves culturally" (p. 302).

King de Ramírez (2015) examined culture specific to particular professions. Her students applied cultural knowledge by developing content for a cultural intelligence (CQ) presentation for community organizations that serve the Latinx community. Creating content for the presentations required students to interact with target language speakers to understand their needs and context. Analysis of student reflections and community partners' evaluations suggested that the project "increased students' knowledge of how culture influences workplace interactions as well as the services that may be provided to Hispanic clients" (p. 65).

Moreno-López et al. (2017) found growth in intercultural awareness among Spanish language students who participated in experiential learning. On open-ended survey items, students "attributed their increased intercultural awareness to their interactions with a diverse group of native speakers who shared their life stories" (p. 406). The authors noted this trend among students who interacted with Spanish speakers in various contexts: study abroad, "telecollaborative" learning online, and CBSL during Saturday programs at the university's Latino Learning Center. This finding thus suggests that, at least in the context of Moreno-López et al.'s students, the interaction with native speakers, rather than the element of CBSL, was associated with intercultural growth.

At the University of Alberta in Canada, Zapata (2011) investigated Spanish language students' attitudes toward the target language and culture through pre- and post- questionnaires with Likerttype items. He compared attitudes among students who completed a CBSL experience at a nonprofit 
organization serving the Latinx community to students who created class cultural presentations. Of the 18 students who participated in the CBSL option, those who started the program with a higher level of Spanish proficiency demonstrated greater gains in cultural understandings, attitudes toward Spanish language in the community, and self-confidence using Spanish in the community than those beginning the program with lower levels of language proficiency. Zapata concluded that cultural growth may be best achieved when students have sufficient proficiency to engage deeply with the community organization.

Other authors reported on cultural outcomes that emerged from the data but that were not reflective of a priori research questions or theoretical frameworks. For instance, Elorriaga (2007) commented on how the CBSL experience worked to dismantle stereotypes that students held about the Latinx community. In an analysis of written reflections from four Chinese university English language students in New Zealand, Andrew (2003) found that students made connections between vocabulary they heard their community partners use and cultural contexts. In Canada, Hummel (2013) facilitated a community-based experience for 20 French-speaking students training to become English teachers. In oral interviews, several students admitted that, prior to the CBSL experience, "they had had little to no pre-existing knowledge of the community or of the existence of Englishlanguage schools in the local area" (p. 79). These articles suggested that cultural learning may occur as an unexpected secondary outcome when interacting with target language community members.

A conclusion that can be drawn from articles in this review is that service-learning experiences are associated with growth in students' cultural learning and their attitudes toward the community. These changes are evidenced through student reflections and perceptions, and they may occur even when instructors do not design the experience explicitly targeting cultural learning outcomes. In general, it appears that students' direct interaction with community members facilitates growth, at least as reported by students.

Motivation and interest. Eleven articles addressed student motivation and interest in learning and using L2. The authors collected data through surveys, open-ended questionnaires, interviews, or journal reflections, and most found evidence supporting positive outcomes. In an early evaluative study, Morris (2001) examined motivations and attitudes of 95 Spanish language students who participated in various CBSL experiences, including tutoring ESL, counseling at women's shelters, and interpreting at local government agencies. He compared students' responses on a pre- and postsurvey with Likert-type items and open-ended responses. He found significant positive changes in motivations and attitudes toward learning Spanish and concluded that "attitudinal change occurs through social contact and social access" (p. 252). While Morris did not include a control group or follow students' attitudes beyond the end of the course, his study stands as one of the first empirical studies on CBSL in L2 education; subsequent authors (e.g., Zapata, 2011) adapted Morris' instruments to explore CBSL in other L2 contexts.

Some authors conceptualized motivation for using L2 by unpacking underlying factors and their complex relationship (e.g., Medina \& Gordon, 2014; Pellettieri, 2011). Pellettieri (2011), for example, used the construct of willingness to communicate in an L2. She connected linguistic selfconfidence, perception of ability, and attitudes toward the language to L2 language use. Pellettieri measured these factors among 18 Spanish language students who tutored ESL for new immigrants for 16 hours over the semester. Quantitative analyses of pre- and post- survey responses revealed that her students grew in linguistic self-confidence and reported reduced anxiety after the CBSL experience. Pellettieri could not attribute the positive changes directly to CBSL, but students' openended reflections suggested that the experience assuaged fears about speaking with native language speakers.

Not all findings on affective factors were positive. Along with the linguistic outcomes discussed previously, Miano et al. (2016) examined advanced language enrollment trends and study-abroad participation as indicators of motivation and interest for L2 learning. Sophomore math and science majors participated in a three-week summer program that required students to prepare Spanishspeaking adults for the U.S. citizenship exam. Over the four years of data collected, authors found 
that the majority of students did not enroll in advanced classes or study abroad. Most participants enrolled in the program to gain linguistic knowledge for their "professional toolbox" (p. 299), and while the program increased L2 use, it did not "bridge to upper-level Spanish literature or culture courses, or necessarily to an interest in studying abroad" (p. 287). Likewise, Medina and Gordon (2014) did not find significant differences in their motivation measure for students participating in CBSL as part of a Spanish phonetics class. In fact, they found that all student groups-especially those who were participating in CBSL-decreased in motivation. The authors proposed possible explanations for this decrease, such as "frustration over communication breakdowns with the native Spanish speakers or perhaps because of a realization that understanding 'real' Spanish was very challenging" (p. 367).

Civic engagement. Six of the articles addressed the extent to which CBSL fostered students' civic engagement. Authors approached civic engagement from different perspectives but all focused on how students understood their role in relation to the larger society, taking up issues of social justice, political activism, and identity. Abbott and Lear (2010) demonstrated the range of socialaction outcomes in their advanced business Spanish language course on entrepreneurship in which students worked at and developed a business plan for not-for-profit agencies or schools. The authors presented a case of a student who transcended course requirements to engage in self-directed social action by implementing his plan with a Boy Scout troop. However, the majority of their students reflected the case of a "middle ground" student who developed a thoughtful plan for improving services at a refugee assistance center but "never took the extra step required to transform his connections into concrete social action ... and instead focused his energy on being a good student" (p. 242). The authors posited that an emphasis on classroom success (i.e., grades, test scores) can thwart social action. They suggested assignments that require students to describe whether and how they impacted their community.

Petrov (2013) and Llombart-Huesca and Pulido (2017) both considered civic engagement from the perspective of HLLs. Petrov understood civic engagement as political and as dependent "on students identifying a community to which they feel they belong and becoming invested in the success of that community" (p. 311). The primary goals of her Spanish and culture course for HLLs related to awareness and involvement in the Spanish-speaking community. HLLs worked with afterschool programs, childcare for working adults, and elder care. Petrov analyzed survey responses and journal assignments from 23 students over two cohorts of the course and found that interacting with the community was effective in "increasing Latino student consciousness, and, consequently, selfempowerment, because they contradict inaccurate ideas about Latino experience and reality propagated by the dominant culture" (p. 320). She noted that students often related their CBSL to personal experiences growing up and that they described "our community" rather than "the community," signaling identification with those individuals they encountered.

Llombart-Huesca and Pulido (2017) demonstrated how HLLs' recognition of their bilingualism as an asset was a means to civic engagement. In their study, 18 Spanish HLLs worked in a self-help center or an after-school language immersion program as part of a Spanish applied linguistics course. In biweekly reports on their interactions, some students wrote that they realized for the first time the diversity that exists within the Spanish-speaking population of their California community. Their HLLs recognized that their bilingualism enabled them to "gain ownership of what they have learned, and develop autonomy and agency of their linguistic abilities" (p. 358).

Some authors commented on civic engagement outcomes that accompanied other outcomes. As part of her study on French learners who taught French lessons for elementary students, Grim (2010) found that most students "felt a sense of accomplishment in the role they held in the community" (p. 618). Jorge's (2011) longitudinal survey study of 160 Spanish language students who had participated in weekly home visits to Mexican families revealed long-term gains in being politically informed, along with other outcomes of cultural appreciation and L2 motivation. However, Jorge found that her CBSL program did not correlate with subsequent political or social activism. She explained that placing students in explicit service roles may encourage formal activism, but "such an 
overt service component would alter the equilibrium of power and change the nature of the relationships between [students] and the families" (p. 47).

Other outcomes. Other outcomes included professional, technical, or academic knowledge specific to students' courses. Sun and Yang (2015) found that their 14 English language students grew in their knowledge of using Web 2.0 tools in designing videos for English-speaking international students at their Taiwanese university. However, they cautioned that students' concern with publishing videos may have distracted them from focusing on presentational oral English, which was the learning goal of the project. In examining their German students' reflections about the website translation project, ter Horst and Pearce (2010) found that, in addition to improving written linguistic skills, the students demonstrated gains in content knowledge about sustainable development issues. King de Ramírez (2015) described the growth in professional skills and publicspeaking abilities of her students because they delivered presentations about culture to community members. Finally, a few study authors commented on how the CBSL experience helped students with their personal career decisions. For instance, both Pascual y Cabo et al. (2017) and Grim (2010) explained that working in schools validated some students' decisions to pursue education as a major area of study. Bettencourt (2015) stated that CBSL experiences exposed students to careers that require the use of Spanish and English.

Non-student outcomes. Two empirical articles did not focus on student outcomes. One was Barreneche and Ramos-Flores' (2013) analysis of service-learning curricula in 40 Spanish language programs. The other was d'Arlach et al.'s (2009) study, which examined the perspectives of community members in a language exchange CBSL program designed to "empower the community members to be on equal ground with their university counterparts" (p. 6). d'Arlach et al. conducted pre- and post- interviews with nine Latinx adult immigrants in the program and found that the participants grew from holding stereotypes about university students to a more nuanced understanding of students as complex human beings who do not necessarily have more knowledge on academic topics than they do. d'Arlach et al. made the case for research that centers on community perspectives, arguing that "if service-learning is bridging the distance between ivory tower and brick houses, transforming neighborhoods, or increasing civic participation, the community members would take notice" (p. 5). While three other empirical articles (i.e., Abbott \& Lear, 2010; Bettencourt, 2015; Frame \& Ballah, 2015) supplemented student outcome data with reflections of community members benefitting from CBSL, only d'Arlach et al. posed a research question focused on the perspectives of the community.

\section{Implications for CBSL in L2 Education}

Authors' recommendations echoed ideas that experts in the service-learning field have long advocated, such as incorporating regular student reflection and forming reciprocal partnerships with community members. Taken together, these articles also offer unique lessons for language education that are applicable to other disciplines.

\section{Variability within L2 CBSL Experiences}

This review revealed a wide range of CBSL in L2 settings. Some authors described structured experiences in which all students worked at the same organization completing tasks that faculty and community leaders defined (e.g., lesson planning and delivery in Grim [2010], translation of medical documents in Martínez \& Schwartz [2012]). Other authors described how students within one course engaged in diverse CBSL experiences, with students sometimes identifying agencies independently (e.g., Abbott \& Lear, 2010; Carracelas-Juncal, 2013). In some programs, CBSL did not involve completing direct service at a community site; rather, students interacted with the Latinx community to learn and assess needs (e.g., King de Ramírez, 2015; Larsen, 2015)

Several authors concluded that the kinds of interactions that students experienced appeared to influence the types of outcomes. For instance, Jorge (2011) suggested that working in agencies to 
carry out services for the community might lead to more civic activism than simply spending time with immigrant families in their homes. Further, Medina and Gordon (2014), who found that a CBSL language exchange did not impact Spanish language learners' phonetic perception skills or motivation, provided a germane conclusion in their call for future work "to pinpoint what kinds of experiential learning statistically impact L2 development" (p. 368). Such research might compare outcomes of students involved in different types of CBSL related to language education. An implication for L2 educators is to think carefully about the precise tasks in which students engage with the community rather than trusting that simply interacting with native speakers will accomplish course goals. Practitioners and researchers from all disciplines might consider this recommendation.

\section{Alignment of Expectations and Language Levels}

Successful CBSL programs matched students' language levels and backgrounds with the roles they were expected to play in the community. In their review of challenges in CBSL, Lear and Abbott (2009) stated that missed opportunities for language learning can occur when students underestimate their proficiency level and feel insecure in the L2, or when they overestimate their proficiency and find themselves in situations where they cannot meet the community partner's need.

Multiple authors in this review noted the importance of aligning student levels with tasks. Frame and Ballah's (2015) qualitative study on French students who taught older adult French learners exemplified the difficulties that can arise when community members' expectations do not match those of the college-aged students. Some adults were disappointed that the French classes were too basic, while some college students felt "uncomfortable in the teacher role, perhaps because they felt unqualified to teach [older adult] advanced learners" (p. 68). Barreneche (2011) described a tutoring program in which her advanced Spanish students taught lessons to fifth-grade native Spanishspeaking students at a dual-language school. Her students complained that the children sometimes used English instead of Spanish, which "had the potential to undermine the [university] volunteers' faith in their Spanish skills" (p. 113). Zapata (2011) also noted how misunderstandings about student proficiency levels led to reduced opportunities for meaningful target language use. She explained that even though the partner organizations were given information about the learners' levels, many of the activities planned for the student volunteers required a higher level of language proficiency than the learners brought. As a result, the organizations asked students to carry out tasks that did not involve interaction with native speakers, which disappointed the students. Zapata recommended that instructors work with community partners to clarify student proficiency levels, course objectives, and reasonable task expectations before beginning CBSL projects.

Zapata's recommendation holds for CBSL outside of L2 settings; faculty might communicate clearly with partners to ensure that students' knowledge and skills match the tasks the community requires. This process might first involve an informal needs assessment through which faculty learn the specific context of the community organization, perhaps observing first-hand the kinds of tasks required. Faculty could also share with the community organization the course syllabi and invite community leaders to meet students prior to initiating the partnership. In the context of language education, the ACTFL proficiency standards and "can-do" statements might serve as tools for describing student language levels.

\section{Reflections as Means to Enhance L2 Proficiency}

Nearly every program described in the literature referred to a reflective component for students, a foundational feature in CBSL programs across disciplines (e.g., Jacoby \& Associates, 1996). In L2 settings where the goal of the course is often language proficiency, reflections offer an opportunity for students to not only analyze their experiences but also improve language skills. The majority of reflections described in this review were completed in the target language. Some authors described adapting commonly used reflective protocols to focus on linguistic gains. For instance, Bettencourt (2015) utilized Ash and Clayton's (2009) DEAL model but asked her Spanish language students to 
record "oral journals," in which they spoke about their CBSL experiences to address speaking and listening learning objectives. The DEAL structure, used to "articulate learning" connected to their experience, "pushed students to express themselves in the target language in ways that moved them toward the higher levels of Bloom's Taxonomy" (p. 486). An exception to target language reflections can be found in Bloom's (2008) study on beginning Spanish students. She explained that her students wrote weekly online reflections in their native language because they "often did not have the Spanish language skills available to reflect accurately on their experiences and emotions" (p. 109).

Reflection also emerged as a catalyst for infusing critical perspectives, especially in work published within the past decade. As Leeman et al. (2011b) stated, programs "risk reifying ideological notions of service as "charity' ... which can reinforce students' negative stereotypes" (p. 485 ) if a critical reflection component is not built into the program. Reflection can extend beyond superficial reactions and engage students in potentially uncomfortable conversations about the systemic issues underlying social conditions. The ACTFL standards' emphasis on communities, connections, and culture challenge educators to go beyond historically accepted goals of simply building L2 proficiency. CBSL is a means to intersect L2 learning with awareness of societal issues for students. Likewise, in other disciplines, CBSL can help students apply the content knowledge and skills acquired in coursework to address social-justice concerns in the community.

\section{Future Directions in Research and Practice}

I conclude this review with recommendations for future work in CBSL in L2 in the areas of program implementation and research methodology.

\section{Heritage Language Learners}

Given the growing population of second- and third-generation immigrants who speak a language other than English at home (often Spanish), the numbers of HLLs will only increase in both university and K-12 contexts (Beaudrie \& Fairclough, 2012). Carracelas-Junal (2013) pointed to Beaudrie, Ducar, and Relaño-Pastor's (2009) survey results suggesting that HLLs express interest in connecting coursework with their Spanish-speaking communities. The burgeoning field of heritage language education is ripe for creative CBSL programs that consider critical issues of language variation and language ownership. Community contexts are opportunities for HLLs to recognize and deploy the strengths they bring as language learners while engaging in issues of language rights activism.

Until the early 21 st century, much research on L2 in general has ignored HLLs, but-as evidenced by the articles in this review-HLL scholarship is now seeping into work on CBSL. Leeman et al. (2011b) advocated that CBSL faculty position HLLs as expert speakers, chipping away at deficit thinking that questions the legitimacy of HLLs' language. To avoid mismatch between learners' skills and community tasks, faculty might also analyze carefully the language that HLLs need to use to perform effectively in the CBSL and then support learners in developing the nuanced discourse patterns specific to particular disciplines or communities.

Potential linguistic and cultural outcomes for CBSL HLLs may vary from those expected for L2 students who are not part of the target language community. The "border crossing" experience historically associated with service-learning for university students may not be relevant for HLLs, as they often occupy some of the same linguistic and cultural identities of community members. For instance, Carracelas-Juncal (2013) suggested creating a reflection prompt for HLLs "that takes into account that not all service-learning projects can be defined as 'border-crossing' experiences" (p. 304). Future research might examine outcomes particularly relevant to HLLs and investigate ways educators can carefully implement CBSL programs that meet the unique strengths and needs of these learners. 


\section{Languages Beyond Spanish}

CBSL programs might expand beyond Spanish language. The preponderance of articles about Spanish language learners may reflect the existence of long-standing university partnerships with Latinx community agencies. As Lear (2012) suggested, a relative abundance of Spanish language articles does not necessarily mean that CBSL is absent in other language programs. Unlike many Spanish departments in liberal arts colleges, less commonly taught language programs are often housed in large research universities that do not reward faculty for conducting or writing about CBSL work. With the changing global stage, metropolitan areas are experiencing an increase of immigrants from other language backgrounds. Dual-language programs in less commonly taught languages continue to grow in popularity (American Councils for International Education, 2017), offering CBSL potential for students of languages other than Spanish. Language instructors from these departments might look to well-established programs in Spanish language to develop innovative partnerships.

\section{Research Methods and Samples}

In the majority of empirical articles in this review, authors presented self-reports of student growth (e.g., surveys, journals) and utilized qualitative methods with sample sizes under 50. These methods reflect practical constraints of conducting research at the nexus of practice in education; CBSL experiences cannot be replicated in a laboratory with clearly delineated variables. While small-scale studies and program descriptions provide rich, nuanced examples that can be applied to other programs, they cannot generalize results to large populations and are often unconvincing to policymakers with the power to prioritize CBSL in university settings. To justify investing time, effort, and financial resources into CBSL, researchers need to produce quasi-experimental research demonstrating the impact of CBSL on students and the community. The small-scale studies reviewed here set the stage for larger impact studies. More rigorous research designs, such as those that include control groups and follow student outcomes beyond the end of the CBSL experiences, have the potential to increase knowledge about CBSL in L2 education as well as other disciplines.

\section{Voices in Research}

The overwhelming perspectives represented in the literature reviewed were those of students; a handful of authors collected data on community members' experiences, and only d'Arlach et al. (2009) centered their study on data from community members. This issue is not unique to the L2 context; addressing the service-learning "ecosystem" in higher education, Bloomgarden (2017) suggested that academia's value on "student learning and knowledge production" drives this "inward focus" (p. 21) on students that many service-learning studies take. Prioritizing community perspectives may not appear to be the most efficient approach to accomplishing the student-learning goals for which instructors are held accountable. However, findings in this review suggest that longlasting student outcomes tended to emerge when students recognized how their work met a real need in the community.

Future research in L2 CBSL can move along the continuum of community-engaged research from "investigator-driven" to "community-driven" research (Hacker, 2013, p. 3). Researchers might examine community members who interact directly with students, leaders of community organizations who facilitate partnerships, and university faculty who help students reflect on their experiences. For CBSL to rest equally on Jacoby and Associates' (1996) metaphorical stool of learning, service, and reflection, more literature that captures perspectives of the community is needed. 
18 | International Journal of Research on Service-Learning and Community Engagement

\section{Notes}

1. Among the 69 articles included in the literature review are those preceded by an asterisk $\left(^{*}\right)$ in the References (below). The full list of articles reviewed is available from the author.

2. Because many authors examined multiple outcomes within the same study, the total number of outcomes exceeds the number of empirical articles identified for the review.

\section{References}

Abbott, A. (2009). Comunidades: Más allá del aula. Upper Saddle River, NJ: Prentice Hall.

*Abbott, A., \& Lear, D. (2010). The connections goal area in Spanish community service-learning: Possibilities and limitations. Foreign Language Annals, 43(2), 231-245.

American Councils for International Education. (2017). The National K-16 Foreign Language Enrollment Survey report: A comprehensive study of foreign/world language enrollments across the formal U.S. education system, K-16. Washington, DC: Author. Retrieved from https://www.americancouncils.org/language-research-fle-state-language-us

*Andrew, M. (2012). Authentic cultural and linguistic learning through practicum in a nursing home. TESL-EJ, 16(1), 1-19.

Ash, S. L., \& Clayton, P. H. (2009). Learning through critical reflection: A tutorial for students in service-learning. Raleigh, NC: Authors.

*Barreneche, G. I. (2011). Language learners as teachers: Integrating service-learning and the advanced language course. Hispania, 94(1), 103-120.

*Barreneche, G. I., \& Ramos-Flores, H. (2013). Integrated or isolated experiences? Considering the role of service-learning in the Spanish language curriculum. Hispania, 96(2), 215-228.

Beaudrie, S., Ducar, C., \& Relaño-Pastor, M. (2009). Curricular perspectives in the heritage language context: Assessing culture and identity. Language, Curriculum and Culture, 22, $157-174$.

Beaudrie, S. M., \& Fairclough, M. (Eds.). (2012). Spanish as a heritage language in the United States: The state of the field. Washington, DC: Georgetown University Press.

*Bettencourt, M. (2015). Supporting student learning outcomes through service-learning. Foreign Language Annals, 48(3), 473-490.

*Bloom, M. (2008). From the classroom to the community: Building cultural awareness in first semester Spanish. Language, Culture and Curriculum, 21(2), 103-119.

Bloomgarden, A. (2017). Out of the armchair: About community impact. International Journal of Research on Service-Learning and Community Engagement, 5(1), 21-23.

Bringle, R. G., \& Hatcher, J. A. (1996). Implementing service-learning in higher education. Journal of Higher Education, 67(2), 221-239. https://doi.org/10.1080/00221546.1996.11780257

Brown, A. V., \& Thompson, G. L. (2018). The changing landscape of Spanish language curricula: Designing higher education programs for diverse students. Washington, DC: Georgetown University Press.

*Bowen, G. A., \& Hackett, P. B. (2010). Developing cultural understanding through Spanishlanguage learning: A service-learning approach. Journal on Excellence in College Teaching, 21(2), 29-43.

*Bugel, T. (2013). Translation as a multilingual and multicultural mirror framed by service-learning. Hispania, 96(2), 369-382.

*Carney, T. M. (2004). Reaching beyond borders through service-learning. Journal of Latinos and Education, 3(4), 267-271.

*Carracelas-Juncal, C. (2013). When service-learning is not a "border-crossing" experience: Outcomes of a graduate Spanish online course. Hispania, 96(2), 295-309. 
*d'Arlach, L., Sánchez, B., \& Feuer, R. (2009). Voices from the community: A case for reciprocity in service-learning. Michigan Journal of Community Service-Learning, 16(1), 5-16.

*Elorriaga, M. (2007). College students as tutors: Learning from the Latino community of Adams County. Hispania, 90(3), 533-542.

Evans, J., \& Benefield, P. (2001). Systematic reviews of education research: Does the medical model fit? British Educational Research Journal, 27, 527-541.

*Frame, D. L., \& Ballah, J. L. (2015). Speaking the same language: A case study in intergenerational interactions to promote understanding across generations. AURCO Journal, 21, 58-71.

Glaser, B. G., \& Strauss, A. L. (1967). The discovery of grounded theory: Strategies for qualitative research. Chicago, IL: Aldine.

Goldberg, D., Looney, D., \& Lusin, N. (2015). Enrollments in languages other than English in United States institutions of higher education, fall 2013. New York, NY: Modern Language Association of America.

*Grim, F. (2010). Giving authentic opportunities to second language learners: A look at a French service-learning project. Foreign Language Annals, 43(4), 605-623.

Hacker, K. (2013). Community-based participatory research. Thousand Oaks, CA: Sage.

Hammersley, M. (2001). On "systematic" reviews of research literatures: A "narrative" response to Evans \& Benefield. British Educational Research Journal, 27(1), 543-554.

Hellebrandt, J., \& Varona, L. T. (1999). Construyendo puentes (Building bridges): Concepts and models for service-learning in Spanish. American Association for Higher Education series on service-learning in the disciplines. Washington, DC: American Association for Higher Education.

*Hummel, K. M. (2013). Target-language community involvement: Second-language linguistic selfconfidence and other perceived benefits. Canadian Modern Language Review, 69(1), 65-90.

Jacoby, B., \& Associates. (1996). Service-learning in higher education: Concepts and practices. San Francisco, CA: Jossey-Bass.

*Jorge, E. (2011). Assessing the value of a community-based approach to language and cultural learning: A longitudinal study. Journal of the Scholarship of Teaching and Learning, 11(1), 33-52.

*Jovanović, A., \& Filipović, J. (2013). Spanish teacher education programs and community engagement. Hispania, 96(2), 283-294.

Kennedy, M. M. (2007). Defining a literature. Educational Researcher, 36(3), 139-147.

*King de Ramírez, C. (2015). Strategy and action: Assessing student-led culture workshops within the professions. Foreign Language Annals, 48(1), 56-67.

*Larson, K. C. (2015). Uniting Hispanic film studies with civic engagement: A chance for personal transformation. Hispania, 98(3), 533-548.

*Leeman, J., Rabin, L., \& Roman-Mendoza, E. (2011a). Critical pedagogy beyond the classroom walls: Community service-learning and Spanish heritage language education. Heritage Language Journal, 8(3), 1-22.

*Leeman, J., Rabin, L., \& Román-Mendoza, E. (2011b). Identity and activism in heritage language education. Modern Language Journal, 95(4), 481-495.

*Lear, D. (2012). Languages for specific purposes curriculum creation and implementation in service to the U.S. community. Modern Language Journal, 96(1), 158-172.

*Llombart-Huesca, A., \& Pulido, A. (2017). Who needs linguistics? Service-learning and linguistics for Spanish heritage language learners. Hispania, 100(3), 348-360.

*Long, D. R. (2003). Spanish in the community: Students reflect on Hispanic cultures in the United States. Foreign Language Annals, 36(2), 223-232.

Looney, D., \& Lusin, N. (2019). Enrollments in languages other than English in United States institutions of higher education, summer 2016 and fall 2016: Final report. New York, NY: Modern Language Association. Retrieved from https://www.mla.org/content/ download/110154/2406932/2016-Enrollments-Final-Report.pdf 
*López, S. (2014). Spanish-language learners and Latinos: Two community-based projects. Journal of Latinos and Education, 13(1), 71-77.

*Martínez, G., \& Schwartz, A. (2012). Elevating "low" language for high stakes: A case for critical, community-based learning in a medical Spanish for heritage learners program. Heritage Language Journal, 9(2), 37-49.

* Medina, A., \& Gordon, L. (2014). Service-learning, phonemic perception, and learner motivation: A quantitative study. Foreign Language Annals, 47(2), 357-371.

*Miano, A. A., Bernhardt, E. B., \& Brates, V. (2016). Exploring the effects of a short-term Spanish immersion program in a postsecondary setting. Foreign Language Annals, 49(2), 287-301.

Modern Language Association Ad Hoc Committee on Foreign Languages. (2007). Foreign languages and higher education: New structures for a changed world. Profession, 12, 234 245.

*Moreno-López, I., Ramos-Sellman, A., Miranda-Aldaco, C., \& Gomis Quinto, M. T. (2017). Transforming ways of enhancing foreign language acquisition in the Spanish classroom: Experiential learning approaches. Foreign Language Annals, 50(2), 398-409.

*Morris, F. A. (2001). Serving the community and learning a foreign language: Evaluating a servicelearning programme. Language, Culture and Curriculum, 14(3), 244-255.

National Standards in Foreign Language Education Project. (1996). Executive summary, Standards for foreign language learning. Alexandria, VA: Author.

National Standards in Foreign Language Education Project. (2015). World-readiness standards for foreign language learning. Alexandria, VA: Author.

*O'Connor, A. (2012). Beyond the four walls: Community-based learning and languages. Language Learning Journal, 40(3), 307-320.

*Ogeyik, M. C., \& Guvendir, E. (2009). Service-learning in distance education: Foreign language learning environments. Turkish Online Journal of Distance Education, 10(1), 9-20.

Palpacuer Lee, C., Curtis, J., \& Curran, M. (2018). Shaping the vision for service-learning in language education. Foreign Language Annals, 51(1), 169-184.

*Pascual y Cabo, D., Prada, J., \& Lowther Pereira, K. (2017). Effects of community service-learning on heritage language learners' attitudes toward their language and culture. Foreign Language Annals, 50(1), 71-83.

*Pellettieri, J. (2011). Measuring language-related outcomes of community-based learning in intermediate Spanish courses. Hispania, 94(2), 285-302.

Perren, J., \& Wurr, A. (2015). Learning the language of global citizenship: Strengthening servicelearning in TESOL. Champaign, IL: Common Ground Publishing.

*Petrov, L. A. (2013). A pilot study of service-learning in a Spanish heritage speaker course: Community engagement, identity, and language in the Chicago area. Hispania, 96(2), 310 327.

Phillips, J. K., \& Abbott, M. (2011). A decade of foreign language standards: Impact, influence and future directions. Report of Grant Project \# P017A080037, Title VII, International Research Studies, U.S. Department of Education to the American Council on the Teaching of Foreign Languages. Retrieved from https:/www.actfl.org/sites/default/files/ publications/standards/NationalStandards2011.pdf

*Rabin, L. (2011). Community service and activism in heritage languages, New York City, 19151956. Foreign Language Annals, 44(2), 338-352.

Slavin, R. E. (1986). Best-evidence synthesis: An intelligent alternative to meta-analytic and traditional reviews. Educational Researcher, 15(9), 5-11.

*Sun, Y.-C., \& Yang, F.-Y. (2015). I help, therefore, I learn: Service-learning on Web 2.0 in an EFL speaking class. Computer Assisted Language Learning, 28(3), 202-219.

Suro, R. \& Singer, A. (2002, July). Latino growth in metropolitan America: Changing patterns, new locations. Washington, DC: Center on Urban \& Metropolitan Policy, The Brookings Institution and The Pew Hispanic Center. 
*ter Horst, E. E., \& Pearce, J. M. (2010). Foreign languages and sustainability: Addressing the connections, communities, and comparisons standards in higher education. Foreign Language Annals, 43(3), 365-383.

Thompson, G. (2012). Intersection of service and learning: Research and practice in the second language classroom. Charlotte, NC: Information Age.

Valdés, G. (2000). Introduction. Spanish for native speakers. In AATSP professional development series handbook for teachers: K-16: Vol. 1 (pp. 1-20). New York, NY: Harcourt College.

Valette, R., \& Disick, R. (1972). Modern language performance objectives and individualization. New York: Harcourt Brace Jovanovich.

*Varona, L. (2006). Teaching to Learn. International Journal of Learning, 12(9), 207-214.

*Varricchio, A. (2006). Service-learning at all levels: From field trips to internships. Hispania, $89(1), 161-163$.

*Wehling, S. (2008). Cross-cultural competency through service-learning. Journal of Community Practice, 16(3), 293-315.

Yorio, P., \& Ye, F. (2012). A meta-analysis on the effects of service-learning on the social, personal, and cognitive outcomes of learning. Academy of Management Learning and Education, $11(1), 9-27$.

*Zapata, G. (2011). The effects of community service-learning projects on L2 learners' cultural understanding. Hispania, 94(1), 86-102.

Zlotkowski, E. (1998). A new model of excellence. In E. Zlotkowski (Ed.), Successful servicelearning programs. New models of excellence in higher education (pp. 1-14). Bolton, MA: Anker Publishing.

\section{About the Author}

Lottie Baker is an Assistant Professor of Curriculum and Pedagogy in the Graduate School of Education and Human Development at The George Washington University.

Correspondence concerning this article should be addressed to Lottie Baker at lottie@gwu.edu. 